\title{
The influence of natural alteration on the quality of spodumene ores
}

\author{
J. CHISCHI $^{1 *}$, H.C. OSKIERSKI ${ }^{1 *}$, M.F. ALHADAD ${ }^{1}$, \\ B. SCHULZ ${ }^{2}$, G. SENANAYAKE ${ }^{1}$, B.Z. DLUGOGORSKI ${ }^{3}$
}

${ }^{1}$ College of Science, Health, Engineering and Education, Murdoch University, Murdoch, WA 6150, Australia (*correspondence: Johannes.Chischi@murdoch.edu.au) ${ }^{2}$ Institute of Mineralogy, Technical University Bergakademie Freiberg, D-09596, Freiberg, Germany

${ }^{3}$ Office of Energy and Resources Institute, Charles Darwin University, Darwin, NT 0909, Australia

Natural alteration poses a significant challenge for the economical processing of spodumene ores into concentrates suitable for conversion into battery grade lithium chemicals. Converter plant specifications of $>6$ wt. $\% \mathrm{Li}_{2} \mathrm{O}$ and $<1$ wt. $\%$ $\mathrm{Fe}_{2} \mathrm{O}_{3}$ for spodumene concentrates result in poor recoveries during processing from deposits with naturally altered spodumene and thus in the loss of valuable lithium to waste [1]. High $\mathrm{Fe}_{2} \mathrm{O}_{3}$ contents in the spodumene concentrate can further lead to clinker formation during calcination, lowering subsequent $\mathrm{Li}$-extraction via leaching [2].

Here we use PXRD, EPMA, LA-ICP-MS and MLA to analyse the mineralogy, geochemical compositions and liberation characteristics of two Western Australian spodumene ores to develop processing strategies for increasing spodumene recovery while maintaining low $\mathrm{Fe}_{2} \mathrm{O}_{3}$ contents. Besides up to 0.9 wt. $\%$ of chemically substituted $\mathrm{Fe}_{2} \mathrm{O}_{3}$ present in spodumene itself, we identify micas among other alteration phases that are finely intergrown with spodumene as the main $\mathrm{Fe}_{2} \mathrm{O}_{3}$ carrier, containing up to 3.2 wt.\%. For one of the ores liberation characteristics are primarily independent of particle size. For the other ore sample particle composition liberation of $90-95 \%$ and expected spodumene recovery of $80-90 \mathrm{wt} . \%$ can only be achieved for smaller particle sizes between 125 and $500 \mu \mathrm{m}$. Depending on alteration, grinding to smaller particle sizes could thus enable the rejection of almost all Fe-rich micas during spodumene processing.

Higher recoveries can offset the energy required for additional grinding and result in increased resource utilisation. Our study highlights that natural alteration of spodumene has a profound effect on ore quality and its suitability for the production of lithium chemicals suitable for the battery market.

[1] La Brooy \& Harman (2018) ALTA Conf. Proc., p. 216.

[2] Aylmore et al. (2020) ALTA Conf. Abs. 